\title{
O DIREITO À SAÚDE NA ORDEM CONSTITUCIONAL BRASILEIRA
}

\section{THE RIGHT TO HEALTH IN THE BRAZILIAN CONSTITUTIONAL ORDER}

Irineu Francisco Barreto Júnior

Miriam Pavani

\section{RESUMO}

Este artigo analisa a inserção do direito à Saúde na Constituição Federal de 1988, em abordagem que a situa no contexto da formação histórica dos direitos sociais no País. Elabora um perfil histórico desse direito no período que antecede a Constituição de 1988, assim como nos vinte anos subsequentes à sua promulgação. Trata da inserção dos direitos sociais na ordem constitucional, em especial o direito à saúde, com ênfase nos princípios da responsabilidade estatal, gratuidade, universalidade do acesso e integralidade da assistência. Conclui que o direito à saúde é um direito fundamental social associado à realização da justiça social, com observância aos princípios da equidade e da universalidade de acesso. Palavras-chave: Direito à saúde. Direitos fundamentais. Direito constitucional.

\begin{abstract}
This article analyzes the inclusion of the Right to Health in the Federal Constitution of 1988 in approach situated in the context of the historical formation of social rights in the country. Also produces a historical profile of this right in the period preceding the 1988 Constitution, as well as in the twenty years following its enactment. Then comes the
\end{abstract}


inclusion of social rights in the constitutional order, in particular the right to health, with emphasis on the principles of state responsibility, gratuity, universality of access and comprehensive care. We would like to conclude that the right to health is a fundamental social right with the implementation of social justice, in compliance with the principles of equity and universal access.

Keywords: Right to health. Fundamental rights. Constitutional law.

\section{INTRODUÇÃO}

O Poder Constituinte de 1988 reconheceu, sob a denominação de direitos sociais, um conjunto híbrido e abrangente de direitos designados de fundamentais pelo Título II da Constituição Federal. O direito à saúde é parte que integra o rol desses direitos sociais. A saúde é estabelecida como um direito universal que deve ser garantido pelo Estado. Assim, o Sistema Único de Saúde (SUS), institucionalizado pela Lei Federal $\mathrm{n}^{\circ}$ 8.080, em 1990 - Lei Orgânica da Saúde (LOS) - possui, como princípios, a universalidade de acesso aos serviços de saúde e a integralidade da assistência, cabendo a ele a execução de ações de assistência terapêutica integral, inclusive farmacêutica ( $\operatorname{art} .6^{\circ}$ ). Ambas, a Constituição Federal e a Lei Federal n 8.080/90 - Lei Orgânica da Saúde - definem o objeto do direito à saúde incorporando o conceito da Organização Mundial da Saúde: "[...] um estado de completo bem-estar físico, mental e social e não apenas a simples ausência de doenças e outros danos".

A Constituição da República Federativa do Brasil de 1988 inseriu o direito à saúde como um direito social (art. $6^{\circ}$ ), entre os direitos e garantias fundamentais. Da mesma forma, instituiu o art. 194 incluindo a saúde no sistema de seguridade social do País, ao lado dos arts. 196 a 201 da CF que, por sua vez, fixaram uma estrutura política complexa e abrangente para o sistema de saúde brasileiro. Em consonância com o preceito constitucional, a Lei n ${ }^{\circ} 8.080$, em 1990 - Lei Orgânica da Saúde - deu ressonância a vários princípios constitucionais e estabeleceu, no art. $2^{\circ}$, que a saúde é um direito fundamental e, no art. $7^{\circ}$, II, prenunciou a assistência integral como conjunto articulado de ações e serviços públicos que propiciem aos indivíduos e à coletividade atenção eficiente e adequada em todos os níveis de complexidade do sistema. A constitucionalização do direito à saúde acarretou um aumento formal e 
material de sua força normativa com inúmeras consequências práticas, sobretudo quanto à sua efetividade, considerada como a materialização da norma no mundo dos fatos, a realização do direito, o desempenho concreto de sua função social.

Este artigo analisa a inserção do direito à saúde na Constituição Federal de 88 , na perspectiva da formação histórica dos direitos sociais. Elabora um perfil histórico desse direito até a promulgação da Carta Constitucional de 88, assim como nos 20 anos seguintes à sua promulgação. Considera que a garantia das conquistas estabelecidas na Constituição de 1988 tem sido um processo árduo, ainda inconcluso, em especial no que diz respeito ao direito social à saúde. É fato que muito se avançou, no entanto muito ainda há a ser feito.

A seguir, trata da inserção dos direitos sociais na Carta Constitucional de 88 , erigidos à categoria de direitos fundamentais, tal como está inserido sob o Título II, "Dos Direitos e Garantias Fundamentais", o que demonstra um compromisso do legislador na construção de uma sociedade mais equânime. Destaca que o preâmbulo do texto constitucional evidencia a vontade dos constituintes de instituir um Estado democrático, que assegure o exercício dos direitos sociais e individuais, liberdade, segurança, bem-estar, desenvolvimento, igualdade e justiça, como valores supremos de uma sociedade fraterna e pluralista, fundada na harmonia social.

\section{DESENVOLVIMENTO HISTÓRICO DA CONSTI- TUCIONALIZAÇÃO DA SAÚDE NO BRASIL}

A importância do tema saúde na agenda mundial adveio de uma aceitação da existência de direitos que pertencem a toda humanidade. Exemplo disso é a Declaração de Istambul, documento publicado em maio de 2009, que marcou o final do Congresso da Federação Mundial de Saúde Pública, realizado na Turquia, e reuniu 70 associações nacionais de saúde pública, entre as quais a Associação Brasileira de Pós-Graduação em Saúde Coletiva (Abrasco) e regionais, como a da Europa, European Public Health Association (Eupha) e da América Latina, Asociación Latinamericana y del Caribe de Educación em Salud Pública (Alaesp). A frase que abre a Declaração de Istambul (Turquia) não deixa margens para questionamentos: “A proteção da saúde da população é 
a primeira responsabilidade dos governos em todos os níveis, entre os quais, em especial, os chefes de Estado e primeiros-ministros". ${ }^{1}$

A amplitude do tema saúde como direito tal como o seu destaque na agenda internacional estão diretamente relacionados com o histórico social e político dos povos. Assim, o conceito de saúde não pode ser entendido sem o recurso aos direitos de liberdade, de igualdade e de solidariedade entre os povos e as gerações. ${ }^{2}$ Para ilustrar a importância da temática saúde na agenda internacional, desde a fundação em 1948 da Organização Mundial da Saúde (OMS), até os dias atuais, a entidade conquistou grandes vitórias para a saúde pública mundial. Um dos mais importantes eventos foi a reunião, em 2000, de 191 nações na Cúpula do Milênio, realizada em New York (Estados Unidos), na qual as nações envolvidas oficializaram um pacto que estabelece oito metas para tornar o mundo mais justo até 2015. Ttrês dos oito objetivos se relacionam diretamente com a saúde. O acordo resultou nos Objetivos de Desenvolvimento do Milênio. As metas são: erradicar a extrema pobreza e a fome; atingir o ensino básico universal; promover a igualdade entre os sexos e a autonomia da mulher; reduzir a mortalidade infantil; melhorar a saúde materna; combater o HIV/AIDS, malária e outras doenças; garantir a sustentabilidade ambiental; e estabelecer uma parceria mundial para o desenvolvimento. ${ }^{3}$

Destaque-se que, conforme Marques, “[...] as Constituições anteriores a de 1988 não tratavam a saúde como um direito" ${ }^{4}$ Uma rápida abordagem das Constituições republicanas nos força a admitir que a inserção do direito à saúde se deu de forma vagarosa no Brasil. O sistema público de saúde brasileiro, até a promulgação da Constituição Federal de 1988, não merecia um tratamento constitucional específico e atendia somente aos indivíduos que contribuíssem com a Previdência Social, ou seja, aqueles indivíduos que possuíssem carteira de trabalho assinada.

Analisando o texto constitucional de 1824, temos, no Título VIII, “Das Disposições Geraes, e Garantias dos Direitos Civis, e Politicos dos Cidadãos Brazileiros", a primeira referência à saúde no contexto constitucional, vista no art. 179. Interessante observar que essa foi a única Constituição a reconhecer a existência de quatro funções do Poder político: Legislativa, Moderadora, Executiva e Judiciária. A função Mo- 
deradora ou neutra consignava a chave de toda a organização política do Império e era delegada privativamente ao monarca.

Em 1860, começam a surgir movimentos de enfraquecimento da Monarquia. Assim, em 15 de novembro de 1889, o Marechal Deodoro da Fonseca proclamou a República, afastando Dom Pedro II do poder, bem como a dinastia de Bragança. Entre 1889 e 1891, foi instaurado o Governo Provisório, por meio do Decreto ${ }^{\circ} 1$, de 15 de novembro de 1889, que foi redigido por Rui Barbosa e presidido por Deodoro da Fonseca. Foi-lhe delegada a importante missão de consolidar o regime republicano e estabelecer a primeira Constituição da República. A Assembleia Constituinte foi eleita em 1890 e, em 24 de fevereiro de 1891, foi promulgada a primeira Constituição republicana do Brasil, denominada Constituição da República dos Estados Unidos do Brazil. Algumas de suas principais características foram: a consagração da tripartição dos Poderes; a separação do Estado e a Igreja; a garantia do direito à propriedade, dentre outros direitos e garantias fundamentais. No que se refere à saúde, na Constituição de 1891, não houve avanços substanciais, uma vez que a Assembleia Constituinte esteve mais focada na mudança das formas de Estado e governo, na criação da República, o que elencou deveres negativos ao Estado. Acrescente-se que a Constituição de 1891 sofreu importante reforma em 1926. A modificação mais importante referiu-se à incorporação do direito do trabalho à Constituição, no entanto uma verdadeira inovação somente se deu com a promulgação da Carta de $1934 .^{5}$

Fruto das mobilizações de 1930, as quais levaram Getúlio Vargas provisoriamente ao poder, e soma-se a isso o levante constitucionalista ocorrido dois anos após, foi promulgada, em 16 de julho de 1934, a Constituição da República dos Estados Unidos do Brasil. Com a ruptura da concepção liberal de Estado, essa Constituição teve por objetivo principal cravar as bases medulares do Estado Social de Direito. Advém daí a sua nítida preocupação e compromisso com a questão social, fazendo com que, desse modo, fosse implantada nessa época a justiça do trabalho, a justiça eleitoral, o voto secreto, o acesso das mulheres à cidadania - com o voto feminino obrigatório, exceto se a mulher não exercesse função pública remunerada. ${ }^{6}$ Vargas criou novos ministérios, como o Ministério do Trabalho, o da Indústria e Comércio e o Ministério da Educação e Saúde, e foram nomeados interventores de Estados. A 
Revolução de 1930 é o marco divisor de águas no País, com a criação do Ministério da Saúde. Observa-se que, no art. $10^{\circ}$ da Constituição de 1934, estão inseridas as competências concorrentes da União e dos Estados e, no inciso II, a obrigação do cuidado à saúde. É a primeira referência constitucional a tratar da legislação do direito à saúde. Além desse artigo, foi incluído ainda o dispositivo que trata da assistência médica e sanitária do trabalhador e da gestante. ${ }^{7}$ Contemplando as Constituições anteriores, esta foi um salto nas políticas públicas de atendimento à população, como consta dos arts. 138, "f" e $140 .^{8}$

Destaque-se que a Constituição de 1934 valeu por cerca de três anos, sendo ab-rogada pela Constituição de 1937, “[...] que pôs termo ao curto período de institucionalidade democrática então vivenciada". 9 Getúlio Vargas foi eleito em 1934, com mandato previsto até 1938, e defendia um Estado autoritário, baseado no modelo fascista. Assim, em 10 de novembro de 1937, Vargas e os militares que o apoiavam suscitaram um golpe ditatorial de Estado. Consequentemente, houve a decretação da Constituição dos Estados Unidos do Brasil de 10 de novembro de 1937 e a instauração da ditadura, chamada de o Estado Novo.

Ressalte-se que essa referida Constituição "[...] foi denominada de 'Polaca', pois Getúlio Vargas, auxiliado por seu Ministro da Justiça, Francisco Campos, e embalado na posição universal de descrença da democracia, foi inspirar-se na Carta ditatorial polonesa de 1935". Essa Constituição “[...] conferiu ao presidente da república o poder de influenciar diretamente nas decisões do judiciário" ${ }^{10}$ No que se refere à proteção da saúde, nesta, houve previsão, no art. 16, com destaque para a proteção da saúde da criança. ${ }^{11}$ Mesmo com a centralização absolutista imposta por Vargas, o texto constitucional continuou com a previsão de proteção à saúde e previu, em seu art. 18, que, em caso de deficiência de lei federal, os Estados legislassem sobre alguns assuntos: assistência pública, obras de higiene popular, casas de saúde, clínicas, estações de clima e fontes medicinais. ${ }^{12}$

Em 1945, Getúlio Vargas manteve manobras políticas arbitrárias que levaram à sua expulsão do poder pelas mãos das Forças Armadas no dia 29 de outubro desse mesmo ano. Nesse cenário, a Constituição de 1937 naufragou junto com o regime ditatorial - o Estado Novo no qual se incorporava. Promulgada em 18 de setembro de 1946, a 
Constituição dos Estados Unidos do Brasil “[...] proveio da redemocratização e reconstitucionalização do Brasil, precedida da queda de Getúlio Vargas, ocorrida em ambiente internacional a ela favorável com o fim da Segunda Guerra Mundial". Destaque-se ainda, a ocorrência “[...] no mundo do pós-guerra, de grande retomada dos princípios constitucionais, modificando as constituições existentes ou criando outras, como as da Itália, França, Alemanha, Iugoslávia, Polônia [...], que influenciaram [...] a reconstitucionalização do País". ${ }^{13}$ No texto constitucional de 1946, houve algumas mudanças quanto à previsão da legislação de garantida à saúde, como exemplo, o fator da competência, exposto no art. $5^{\circ} .{ }^{14}$

Vale lembrar que a Constituição Republicana de 1967, projeto de Carlos Medeiros Silva, ministro da Justiça, foi formalmente "[...] discutida, votada, aprovada e promulgada pelo Congresso Nacional, que se reuniu, em caráter extraordinário [...]". No exercício da presidência da República estava o então Marechal Castelo Branco que foi

[...] movido pela necessidade de dar ao país uma constituição que, além de uniforme e harmônica [...], editou o Ato Institucional $n^{\circ} 4$ [...], mediante o qual convocou o Congresso nacional para se reunir, no período de 12 de dezembro de 1966 a 24 de janeiro de 1967, com um único objetivo: discutir, votar e promulgar o projeto de Constituição [...]. ${ }^{15}$

Segundo Dallari, “[...] não se pode falar, portanto, em caráter 'semi autoritário' da carta de 1967, mas em um procedimento inelutavelmente autoritário de outorga da Constituição". ${ }^{16}$

A Carta Magna de 1967 concentrou bruscamente o poder no âmbito federal, conferindo amplos poderes ao presidente da República, reduzindo a liberdade individual e suspendendo direitos e garantias constitucionais, naquilo que revelaria a face sombria daquele regime de força: o Comando Militar da Revolução. Enfatiza-se que, " [...] com o golpe militar de 1964, iniciou-se no Brasil um regime em que predominava uma forte tendência à centralização do poder e à redução da esfera da tomada de decisões - reduzida aos limites de Brasília sob forte tutela do grupo militar dirigente".${ }^{17}$ Dos dispositivos constitucionais referentes à saúde, estes aparecem novamente ligados aos direitos dos trabalhadores conforme art. 158, IX e XV. ${ }^{18}$ 
Cumpre observar que, a partir de 17 de outubro de 1969, “[...] a Constituição Brasileira de 1967 sofreu significativa e substancial reforma, através de emendas aditivas e supressivas". Considerando Bulos em contraposição a José Afonso da Silva, o primeiro adere à corrente na qual não considera a emenda Constitucional nº 1 de 1969 como sendo nova Constituição. Mas, parcela de estudiosos, entre eles José Afonso da Silva, dispõe que “[...] teórica e tecnicamente, não se tratou de emenda, mas de nova constituição, [...] uma vez que verdadeiramente se promulgou texto integralmente reformulado, a começar pela denominação que se lhe deu: Constituição Federativa do Brasil, enquanto a de 1967 se chamava apenas constituição do Brasil". ${ }^{19}$ No que tange à proteção da saúde, o seu núcleo não foi estruturalmente alterado. ${ }^{20}$

Superada a longa era de autoritarismo, a promulgação da Constituição Federal de 1988 se deu após padecimentos e inquietações, dando por encerrado o dilatado período de abusos dos governos opressores que se haviam desabado sobre o País. Após mais de ano e meio de estudos e discussões, nasceu a Constituição democrática do novo Brasil, há muito, clamada e ansiada. Preparada pela Assembleia Nacional Constituinte, reunida pela Emenda Constitucional n ${ }^{\circ} 26$, de 27 de novembro de 1985, a Constituição Brasileira de 1988 inspirou-se no texto português de $1976 .{ }^{21}$ Ulisses Guimarães, então presidente da Assembleia Nacional Constituinte, chamou a Constituição Brasileira de 1988 de Constituição Cidadã, tendo em vista a ampla participação popular na sua feitura e a constante busca de efetivação da cidadania. Conforme Barreto Junior, “[...] a realização da Assembleia Nacional Constituinte, entre 1987 e 1988, configurou-se em um dos momentos mais férteis da democracia brasileira, após o regime militar de 1964". ${ }^{22}$ A Carta Magna vigente inaugura um novo sistema de proteção social, informada pelo primado do trabalho e guiada pelo princípio de realização do bem-estar e justiça sociais. A proteção social é orientada pela concepção de Seguridade Social que universaliza os direitos sociais, concebendo a saúde, a assistência social e a previdência como questões públicas e de responsabilidade do Estado, refletidas em seus artigos que serão esmiuçados na seção que segue. 


\section{A CONSTITUIÇÃO DE 1988 E A PROTEÇÃO AO DIREITO SOCIAL À SAÚDE}

O direito à saúde, no período anterior à promulgação da Constituição Federal de 88, trilhou caminhos de exclusão e de centralização no nível federal do sistema público de saúde. No mesmo sentido, Barreto Jr. se manifesta:

As políticas sociais no Brasil recente foram submetidas a profundas transformações, a partir do processo de transição democrática e, em especial, após a promulgação da Constituição de 1988. A Carta determinou que uma série de políticas, antes promovidas e de responsabilidade do governo central, passassem a ser executadas pelos municípios, transformando o desenho institucional e a engenharia técnica-política da teia de proteção social brasileira. Destaca-se, entre as políticas que passaram a ser de responsabilidade municipal, a da saúde, que foi submetida ao mais profundo processo de municipalização já ocorrido na política social do país. ${ }^{23}$

Ocorre que, visando a abrandar a situação de exclusão gerada pelo sistema vigente à época, algumas iniciativas governamentais foram desenvolvidas na década de 1970 e 1980, com o objetivo de ampliar a legitimidade do regime autoritário. Entre as medidas adotadas, podemos mencionar a criação, em 1971, do Fundo de Assistência e Previdência do Trabalhador Rural (Funrural). Esse programa determinou o direito às aposentadorias por velhice e invalidez, à pensão, ao auxílio funeral, ao serviço de saúde e ao serviço social para o trabalhador do campo e seus dependentes. ${ }^{24}$ Em 1974, o Plano de Pronta Ação (PPA) estendeu a proteção da assistência médica a qualquer pessoa em situações de urgência e emergência, independentemente da posse de vínculo previdenciário. Tais iniciativas representaram uma tentativa de ampliar o acesso à assistência médico-hospitalar previdenciária. Em que pesem todas essas iniciativas, “[...] estima-se que à época cerca de metade da população não estava coberta por nenhum sistema previdenciário e dependia da caridade de algumas instituições filantrópicas" ${ }^{25}$

Nas décadas de 1950 a 1970, as concepções do sanitarismo desenvolvimentista (saúde vinculada à concepção de desenvolvimento econômico e social) defendiam a ideia de que a saúde é um bem de valor 
econômico e que investimentos em capital humano eram fundamentais para o desenvolvimento e o progresso das nações, especialmente nos países subdesenvolvidos. Dessa forma, fortes críticas eram feitas às iniciativas governamentais que tinham por objetivo implementar medidas isoladas de ampliação da assistência médica e combate às enfermidades endêmicas. Portanto, “[...] a concepção de saúde como sendo uma condição social e politicamente determinada remonta, no Brasil, ao que se costuma chamar de sanitarismo desenvolvimentista" ${ }^{26}$

Assim, a evolução dos conceitos do sanitarismo desenvolvimentista "[...] permitiu aos estudiosos sair do enfoque centrado na relação médico-paciente, para discutir o trabalho em saúde e a organização de sistemas de saúde" ${ }^{27} \mathrm{O}$ movimento sanitarista da década de 70 tinha como ideário a democratização das relações entre a sociedade e o sistema de saúde. Resumidamente, pode-se afirmar que foram quatro os pontos doutrinários centrais e ainda não é demais mencionar que eles foram decisivos para a formulação dos artigos referentes à saúde na nova Constituição. ${ }^{28}$

O apogeu das mobilizações realizadas pelo movimento dos sanitaristas ocorreu em 1986, com a VIII Conferência Nacional de Saúde. Encontrava-se a sociedade brasileira, nesse momento, em pleno processo de redemocratização do País e na perspectiva da convocação de uma assembleia constituinte. Por ocasião da realização da VIII Conferência, esta recomendava que o setor de saúde deveria ser progressivamente estatizado, assim, também o rigoroso controle sobre a qualidade dos serviços prestados pelos provedores privados contratados. Acrescente-se ainda que estabelecia que as atribuições das três esferas de governo deveriam estar fundamentadas.

A partir desses levantamentos, cabe-nos inferir que o texto constitucional aprovado em 1988, assim chamado de Lei Orgânica da Saúde, Leis $n^{\circ} 8.080 / 1990$ e $n^{\circ} 8.142 / 1990$, aceitou a maior parte das proposições da VIII Conferência.

\section{PRINCÍPIOS CONSTITUCIONAIS DA SAÚDE}

Para se compreender os princípios que norteiam o direito social à saúde, é necessário analisar a vontade do constituinte em prescrever 
o Título VIII “Da Ordem Social” em título específico, pois conforme Bulos, "[...] no ordenamento constitucional passado, a ordem social vinha contida na própria ordem econômica. [...] a Constituição de 1988 a prescreveu em título específico, não apenas para salientar a sua importância, mas para dar continuidade ao programa encampado pelo art. $6^{0 \prime} .{ }^{29}$ Desse modo, o Título VIII, "Da Ordem Social”, integra-se a seu Título II, o qual contém o Capítulo II "Dos Direitos Sociais", fazendo parte integrante dos Direitos e Garantias Fundamentais, "[...] devendo para tanto, o intérprete conciliá-los à medida do possível". ${ }^{30}$

A Constituição Federal anuncia ser direitos sociais a educação, a saúde, o trabalho, a moradia, o lazer, a segurança, a previdência social, a proteção à maternidade e à infância, a assistência aos desamparados $\left(\mathrm{CF}\right.$, art. $\left.6^{\circ}\right)$. Infere-se, portanto, que os princípios elencados no art. 194 da Constituição Federal, relativos à seguridade social, aplicam-se indistintamente aos três direitos dispostos no mesmo artigo: à saúde, à previdência e à assistência social. Coaduna-se com essas reflexões Cordeiro, ${ }^{31}$ quando ressalta que "As políticas de saúde (SUS), de previdência social e de assistência social se pautariam pelos princípios constitucionais $[\ldots]]^{\prime \prime}$ relacionados pelo legislador:

- [...] a universalidade de cobertura e atendimento,

- uniformidade e equivalência de benefícios e serviços às populações urbanas e rurais;

- seletividade e distributividade na prestação de benefícios e serviços;

- irredutibilidade do valor dos benefícios;

- equidade da forma de participação no custeio;

- diversidade da base de financiamento;

- caráter democrático e descentralizado de administração, mediante gestão quadripartite, com participação dos trabalhadores, dos empregadores, dos aposentados e do Governo nos órgãos colegiados.

É importante enfatizar que, conforme Bastos nos ensina, “[...] os princípios consagrados constitucionalmente servem, a um só tempo, como objeto da interpretação constitucional e como diretriz para a atividade interpretativa". ${ }^{32}$ Em suma, os princípios constitucionais adotados pelo legislador constituinte impõem um desafio, nos dias 
atuais, para a sua concretização. Destaca-se que o direito social à saúde, positivado pelo art. 196 da Constituição Federal Brasileira, depende da elaboração e implementação de uma política pública para ser efetivado. Ainda é o mesmo art. 196 da Constituição Federal que garante o acesso universal à saúde, trata-se de norma programática, como foi admitido pelo ministro Celso de Melo, no RE n ${ }^{\circ}$ 271.286-AgR, ReI. min. Celso de Mello, julgamento em 12-9-2000, Segunda Turma, Df de 24-11-2000.

A interpretação da norma programática não pode transformá-la em promessa constitucional inconsequente. O caráter programático da regra inscrita no art. 196 da Carta Política - que tem por destinatários todos os entes políticos que compõem, no plano institucional, a organização federativa do Estado brasileiro - não pode converter-se em promessa constitucional inconsequente, sob pena de o Poder Público, fraudando justas expectativas nele depositadas pela coletividade, substituir, de maneira ilegítima, o cumprimento de seu impostergável dever, por um gesto irresponsável de infidelidade governamental ao que determina a própria Lei Fundamental do Estado". ${ }^{33}$

Ressalta-se ainda a multiplicidade de significados de que esses princípios estão contidos, a exemplo da universalidade, bem como da integralidade que representam os principais desafios a serem enfrentados pelo sistema de saúde do País.

\section{SAÚDE: RESPONSABILIDADE ESTATAL}

Denomina-se de Ordem Constitucional da Saúde o elenco de dispositivos constitucionais alusivo ao direito à saúde, evidenciado pelo art. 196 e combinado com os direitos sociais fundamentais dispostos no art. $6^{\circ}$. Os princípios constitucionais do direito à saúde estão incluídos na Carta “[...] em especial a universalidade e a descentralização das políticas, além da responsabilização do Estado em assegurar o acesso às condições de saúde, através do ditame inserido no texto constitucional: saúde, um direito de todos e um dever do Estado". 34

Assinala-se que a expressão "direito de todos e dever do Estado" contém em seu bojo pretensão universalizante desse direito, portanto entrega ao Estado a responsabilidade pela saúde. OSupremo Tribunal Federal, sensível aos princípios consagrados no texto Constitucional, 
por meio do iminente ministro Celso de Mello, em suas palavras, admite que "[...] o direito público subjetivo à saúde representa prerrogativa jurídica indisponível assegurada à generalidade das pessoas pela própria Constituição da república (art. 196)". Acrescenta ainda a responsabilidade do Poder Público na formulação e na implementação de políticas públicas com o objetivo de garantir o acesso universal e igualitário à assistência farmacêutica, médico-hospitalar e completa: "[...] O direito à saúde - direito fundamental - representa consequência constitucional indissociável do direito à vida. O Poder Público, [...] não pode mostrar-se indiferente ao problema da saúde da população, sob pena de incidir, [...], em grave comportamento inconstitucional" ${ }^{35}$

No texto constitucional, foram estabelecidas as seguintes referências fundamentais sobre as políticas públicas referentes à saúde:

Determina a saúde como direito de todos e dever do Estado (Art. 196). Define o caráter de relevância pública de ações e serviços de saúde (Art. 197), com o que ficam justificadas sua regulamentação e fiscalização pelo poder público, especialmente pelo Ministério Público (MP).

Declara a saúde livre à iniciativa privada (Art. 199).

Define a forma de organização, os princípios, o financiamento e as competências do SUS e o caráter complementar da participação do setor privado (Arts. 198, 199 e 200). ${ }^{36}$

Cumpre observar que o art. 196 da Carta adota uma compreensão social da saúde pautada pela noção de risco. Isso quer dizer que a postura do constituinte originário foi a de adotar uma visão epidemiológica da determinação social da saúde. Prova-se isso pelos termos cunhados pelo constituinte ao elaborar o artigo em questão "[...] redução do risco de doença e outros agravos [...]". Frisa-se que o objetivo do artigo em comento deve ser compreendido amplamente, não apenas como visão utilitarista do bem-estar, mas como risco de morbidade e mortalidade. Um segundo destaque deve ser reservado para a expressão contida no artigo, não menos importante, “ [...] acesso universal e igualitário às ações e serviços para sua promoção, proteção e recuperação", o que revela uma orientação de política pública a fim de garantir ações e serviços relativos à saúde, cujos princípios são 
universalistas e equânimes. Assim, para concretizar todos os objetivos almejados pelo constituinte - "acesso universal e igualitário às ações e serviços" - a essa rede pública de ações e serviços, nomeou o constituinte de Sistema Único de Saúde (SUS), cuja organização e princípios são tratados no art. 198.

Salienta-se ainda que à ideia de responsabilidade estatal pela saúde deve ser agregada não apenas a responsabilidade à prestação de serviços públicos, mas também a sua regulamentação, fiscalização e controle. Entendimento adotado pelo art. 197 da Carta Magna que confere as ações e serviços de saúde como de importância pública, não fazendo distinção quando esse serviço é prestado diretamente pelo Estado ou quando é executado por pessoa física ou jurídica de direito privado. Conclui-se que a Constituição dispõe sobre os condicionantes - "saúde, direito de todos e dever do Estado" -, cabendo, ainda, ao mesmo ente estatal o dever de regulamentação, fiscalização e controle, nos termos da lei e que a "[...] a assistência à saúde é livre à iniciativa privada", respectivamente arts. 196, 197 e 199 da Carta Magna. Dessa forma, pode-se inferir que a saúde é direito exigível por todos. Eis que subjetivo, pode ser cobrado contra todos aqueles entes, estatal ou privado. Acrescente-se que cabe ao Estado a direção da prestação de serviços e ações de saúde, devendo fixar as diretrizes e parâmetros para o exercício destes. ${ }^{37}$

\section{ACESSO UNIVERSAL E IGUALITÁRIO}

A universalidade do acesso é uma das bases do Sistema Único de Saúde, como efetivação do direito à prestação de bens e serviços que concretizam a saúde como um direito de todos e um dever do Estado. Do mesmo modo, o princípio constitucional da igualdade de condições também faz parte das diretrizes elencadas pelo Sistema Único de Saúde, sistema esse criado pela Constituição Federal de 1988. No art. 196 da CF, segunda parte, está previsto expressamente o acesso universal e igualitário às ações e serviços de saúde. Reafirma-se que o direito à saúde se insere na categoria jurídica dos direitos fundamentais, portanto o princípio da universalidade e da igualdade, destacado, ainda uma vez, na parte final do art. 196, resulta de uma redundância jurídica. Assim, se a saúde integra a ordem dos direitos 
fundamentais, está implícita em seu comando a ordem de pertencer ao ser humano como gênero, não podendo, portanto, ficar limitada a um grupo, categoria ou classes de pessoas.

A decisão de redizer o princípio da universalidade e da igualdade, pelo legislador, remonta a raízes históricas. É sabido que, no período precedente à promulgação de nossa atual Constituição, a prestação da saúde foi concebida, por um longo período, como uma prestação previdenciária, a exemplo do Instituto Nacional e Previdência Social (INPS) e do Instituto Nacional de Assistência Médica da Previdência Social (Inamps). Desse modo, só faziam jus ao atendimento estatal aqueles que contribuíram para a previdência. Por óbvio, o sistema dessa maneira organizado gerava a exclusão ao amparo de um grande número de indivíduos, acima de tudo daqueles que se encontravam em situação de desemprego, que não podiam pagar a contribuição previdenciária. Portanto, diferentemente do sistema anterior, no qual se exigia a contribuição pecuniária para ser beneficiado pela assistência, a cidadania passou a ser requisito exclusivo para o acesso e, assim, todos aqueles que se encontraram fora do abrigo do direito à saúde passaram a fazer jus a ele, fato que faz do Sistema Único de Saúde “[...] uma das maiores políticas de inclusão social do país". ${ }^{38}$

Vale lembrar que o direito à saúde é garantia fundamental conferida a todo ser humano - só por sê-lo - portanto o acesso a esses serviços de atenção deve se dar em âmbito nacional, indistintamente.

Ressalta-se que não apenas a Constituição Federal, art. 196, mas, do mesmo modo, o disposto pela Lei n ${ }^{\circ}$ 8.080/1990 - Lei Orgânica da Saúde -, em seu art. $7^{\circ}$, IV, preveem a "[...] igualdade da assistência à saúde, sem preconceitos ou privilégios de qualquer espécie". $\mathrm{O}$ princípio da universalidade mostra-se evidente quando, por exemplo, ocorre o combate à dengue, na vacinação, na fiscalização de alimentos, medicamentos e no controle da qualidade da água, entre outras atividades feitas pelo SUS por meio da vigilância sanitária. No entanto, há as diferenças regionais do País, a dificuldade de acesso à assistência nas periferias das grandes cidades, assim como nas populações ribeirinhas de outras tantas regiões brasileiras. Nesse ponto, não há como não questionar o malferimento do princípio constitucional da universalização e da igualdade, quando os juízes, ao proferirem ordens judiciais, ferem 
esses conceitos - universalização e igualdade -, garantindo a poucos indivíduos que têm pouca ou nenhuma fragilidade social determinados tratamentos e medicamentos que não fazem parte daqueles que são oferecidos pelo SUS. Ressaltam Borges \& Ugá, que “[...] algumas decisões representam verdadeira violação ao princípio da isonomia [...], uma vez que o fornecimento de determinado medicamento não padronizado [...] pode representar a falta de outros para o restante da coletividade, contribuindo, [...] para acentuar as iniquidades dentro do sistema de saúde". 39

Destaca-se que a aplicação do princípio da igualdade pressupõe tratar desigualmente os desiguais. Portanto, uma pessoa que possua condições econômicas mais favorecidas pode sim fazer uso de qualquer serviço público de saúde, desde que em condições de igualdade com os demais cidadãos. Coaduna-se com essas reflexões Oliveira et al., quando ressaltam que a Lei n ${ }^{\circ}$ 8.080/90 - Lei Orgânica da Saúde:

[...] dispõe sobre o dever do Estado em fornecer condições para 'acesso universal e igualitário' (artigo $2^{\circ}$ ) às ações e aos serviços. Porém, tendo em vista o disposto no artigo $3^{\circ}$, de que a ação do Estado não exclui as ações da pessoa e dos elementos constitutivos da sociedade, pode-se argumentar que esta lei propõe caminhos solidários para o alcance das metas de saúde. Estabelecer-se-ia aí o elo com a equidade. As disposições desta lei, determinando acesso universal, não implicariam, necessariamente, acesso gratuito. Tratando como iguais os desiguais, a gratuidade também não auxiliaria na formação da cidadania e na incorporação de mecanismos de solidariedade e responsabilidade na dinâmica social. ${ }^{40}$

Outro fator que contribui para outros questionamentos quanto à aplicação do princípio da universalidade e da igualdade é a inevitável escassez de recursos. A efetivação dos direitos sociais implica custos, não há como negar que a reserva do possível é um dos pontos de dificuldades na implementação de tais direitos. Sobre a origem do termo "reserva do possível" e seu conceito, Kelbert infere:

A reserva do possível foi desenvolvida na Alemanha para solucionar a restrição do número de vagas (Numerus clausus) em algumas Universidades. No caso, julgado em 18 de julho de 1972, analisou-se o art. 
12, § 10 da Lei Fundamental, segundo o qual: todos os alemães têm o direito de eleger livremente a sua profissão, o lugar de trabalho e o lugar de formação. Na referida decisão, esses direitos foram cotejados à luz dos princípios da igualdade e do Estado Social. Ali o que se discutiu foram os diversos critérios de admissão ao ensino superior, bem como a situação dos candidatos que se inscreveram em mais de uma universidade ou em mais de um curso de graduação. Como solução a esses problemas, o Tribunal Constitucional Federal da Alemanha decidiu que algumas prestações estatais ficam sujeitas àquilo que o indivíduo pode exigir da sociedade de forma razoável, ou seja, há prestações que ficam restritas a uma reserva do possível. ${ }^{41}$

No entanto, para Olsen, a reserva do possível “[...] costuma estar relacionada com a necessidade de se adequar às pretensões sociais com as reservas orçamentárias, bem como a real disponibilidade de recursos em caixa para a efetivação das despesas". Acrescenta ainda que a reserva do possível deve ser abalizado como uma "[...] condição da realidade que influencia na aplicação dos direitos fundamentais" ${ }^{42}$

Já Krell submete a teoria da reserva do possível à disponibilidade de recursos econômicos, estando a liberação vinculada à disponibilidade de recursos e ao julgamento discricionário, no âmbito administrativo e juízo legislativo, ou seja, a disponibilidade financeira está vinculada à possibilidade orçamentária pública. ${ }^{43}$

No que se refere ao âmbito do direito constitucional brasileiro, a Constituição de 1998 não possui regra semelhante ao do Direito alemão. Conforme prescrição expressa do art. 109, § $2^{\circ}$, da Lei Fundamental Alemã: (A Federação e os Estados devem tomar em consideração, em seu regime orçamentário, as exigências do equilíbrio da economia no seu conjunto), mas a Constituição de 88 apenas ordena de modo genérico que alguns percentuais de arrecadação de tributos sejam destinados a certas atividades, como saúde ${ }^{44}$ e educação. ${ }^{45}$

Assim, não há como evitar indagações diante do dilema "dar tudo a todos", na área da saúde. Existe viabilidade no contexto fático? Responder coerentemente a essa formulação implica dizer que a "[...] alocação de recursos deve considerar as necessidades desiguais dos indivíduos, com o objetivo de reduzir as desigualdades existentes" ${ }^{46}$ 
Nessa linha, o constituinte de 1988 reforçou os princípios da universalidade e da igualdade, em várias passagens pela Constituição Federal de 1988, e aos intérpretes do Direito cabe aplicá-los ao caso concreto, atentos para que políticas minimizadoras das desigualdades em saúde não se transformem em instrumento auxiliar da perpetuação dessas iniquidades.

\section{A GRATUIDADE}

A gratuidade da assistência à saúde é importante princípio constitucional desdobrado de vários comandos constitucionais. Em decorrência deste, proíbe-se toda e qualquer forma de cobrança do usuário por ações, serviços e equipamentos públicos de saúde. Deflui ser o princípio da gratuidade implícito, eis que a Constituição de 1988 não faz referência expressa à gratuidade, a despeito de estabelecer que saúde é “[...] direito de todos e dever do Estado" (CF, art. 196), assim, nesse caso, estaria implícita no comando do artigo citado e, portanto, dispensa o que seria uma referência redundante. No entanto, assinala-se que a gratuidade da prestação do serviço de saúde está expressa na Lei Orgânica da Saúde, Lei no 8.080/1990, art. 43: “[...] a gratuidade das ações e serviços de saúde fica preservada nos serviços públicos contratados, ressalvando-se as cláusulas dos contratos ou convênios estabelecidos com as entidades privadas".

Outra justificativa para a gratuidade da assistência à saúde decorre da própria natureza do Direito. Assim o direito saúde é direito a ser exercido sem entraves, sem empecilhos, pois o acesso universal e igualitário veda, em seu próprio comando, qualquer cobrança pecuniária para ser exercido. Coaduna-se com essas reflexões Nascimento, quando ressalta que:

[...] no art. $6^{\circ}$ da Constituição, a saúde é direito social e, [...] que se qualifica de inderrogável, e indisponível [...]. Além de direito de todos, é dever do Estado assegurá-lo eficientemente [...]. Nesse liame direito-dever, [...] o direito à saúde é prestado gratuitamente, o beneficiário nada paga, visto que o financiamento das despesas com a execução desse direito é coberto por toda a coletividade. ${ }^{47}$ 
As constituições imediatamente anteriores à de 1988 foram pouco explícitas em relação à saúde em geral, e muito menos ainda quanto ao componente médico-assistencial. A Constituição de 1946 menciona tão somente a garantia de atenção neonatal gratuita à mãe e à criança. A Carta seguinte (1967) ampliou o espectro assistencial, que passou a compreender a "[...] assistência sanitária, hospitalar e médico- preventiva" (CF, art. 165, § XV), mas manteve a cobertura restrita aos trabalhadores.

Assim, conforme Nelson Nery e Rosa Nery, apud Dallari, “[...] no Estado democrático de Direito, a realização dos direitos sociais, econômicos e culturais tem seu suporte financeiro nos impostos, e.g., ensino básico gratuito, serviços de saúde etc." ${ }^{48}$ Como é da composição dos direitos sociais atingir a igualdade, desse modo é o Estado o responsável em garantir os meios para realizar as prestações idealizadas nas ações e serviços de saúde.

\section{A INTEGRALIDADE}

Soma-se aos princípios da universalidade, da igualdade e da gratuidade da assistência - o não menos importante - princípio da integralidade da assistência. Em termos normativos, o referido princípio está previsto primeiramente na Constituição Federal, art. 198, II “[...] atendimento integral, com prioridade para as atividades preventivas, sem prejuízo dos serviços assistenciais; [...]", assim como também na Lei $n^{\circ}$ 8.080/1990 - Lei Orgânica da Saúde -, em seu art. 7º, II: “[...] integralidade de assistência, entendida como um conjunto articulado e contínuo das ações e serviços preventivos e curativos, individuais e coletivos, exigidos para cada caso em todos os níveis de complexidade do sistema; $[. . .]^{\prime \prime}$.

A integralidade do atendimento refere-se ao cuidado das necessidades dos indivíduos, por parte do Estado, de uma maneira ampliada. Mas não apenas, inclui-se também como significado do termo a promoção da saúde, a prevenção, a recuperação e a reabilitação. Isso quer dizer que "[...] o dever do Estado não pode ser limitado, mitigado ou dividido, pois a saúde, como bem individual, coletivo e de desenvolvimento, pressupõe uma abordagem assistencial completa, vale dizer, 
integral, envolvendo todos os aspectos a ela relacionados" ${ }^{49} \mathrm{O}$ princípio da integralidade pressupõe que a prestação do serviço de saúde seja feita em todos os níveis, conforme a necessidade da coletividade. Vale lembrar que não bastaria ao Estado brasileiro focar a atenção da saúde apenas na prevenção, se for ignorada a existência de necessidades particulares, associadas à idade, ao gênero, à etnia, a padrões culturais, que o sistema deveria respeitar. A mesma ideia sobre o conceito do princípio da integralidade revela-se na fala da representante do Conselho Nacional dos Direitos da Mulher (CNDM), Carmen Barroso:

O direito à saúde implica em atenção especial às necessidades específicas de saúde de cada setor da população. As mulheres, por sua dupla carga de trabalho - no lar e fora do lar - e por seu papel especial de reprodutoras da espécie, apresentam problemas específicos de saúde que não podem ser ignorados pela rede de serviços públicos. Esses devem ser abordados de forma integrada $[\ldots] .{ }^{50}$

Outrossim, a integralidade da assistência, no art. $7^{\circ}$ da Lei Orgânica da Saúde $n^{\circ}$ 8080/90, é definida como “[...] conjunto articulado e contínuo das ações e serviços preventivos e curativos, individuais e coletivos, exigidos para cada caso em todos os níveis de complexidade do sistema". Entende-se que integralidade não pode ser interpretada como totalidade, como todo e qualquer insumo, como todo e qualquer medicamento. $\mathrm{O}$ conceito de integralidade da assistência, compreendido como sinônimo de totalidade, não pode prevalecer, eis que é absolutamente inviável. Também é esse o entendimento do subprocurador-geral do Estado do Rio de Janeiro:

Defendemos a generosidade doSUS como programa da nação brasileira. Mas não existe nenhum país do mundo - e estou comparando com os países mais desenvolvidos, com os melhores sistemas de saúde pública, expressamente o reino Unido, a Suécia, a Noruega, o Canadá, a Nova Zelândia -, em nenhum país do mundo há um sistema, por mais rico e generoso que seja, que admita todo e qualquer tratamento, todo e qualquer insumo, todo e qualquer medicamento; [...]. Se essa questão não for enfrentada, o SUS, sem a menor dúvida, correrá um risco, e, cada vez mais recursos orçamentários serão destinados a menos pessoas que têm o acesso à Justiça. ${ }^{51}$ 
Ressalta-se que integralidade é um termo polissêmico, pois, em conceito amplo, deve ser pensada como na "[...] integralidade do sistema em si, pois este agrega ações, atividades e políticas de promoção à saúde, de prevenção à doença, de terapêutica de doenças e de cuidados paliativos". ${ }^{52}$

É importante mencionar que: "[...] a tomada de decisões coletivas pelo sistema político é expressa através da política pública, com observância do princípio da integralidade. E esta política pública, por sua vez, é revestida de uma forma jurídica válida perante o direito" ${ }^{53}$ Nesse ínterim, é preciso mencionar parte do discurso de Nardi:

Foi mencionado neste fórum que alguns juízes de primeira instância têm tido dificuldade no julgamento inicial, pois nem sempre dispõem de informações e conhecimento para tomar decisões imediatas, o que os leva a encaminhar aos gestores municipais para que providenciem exames e terapias especializadas que extrapolam as suas competências. De outro lado, temos também dificuldades com os gestores municipais de inúmeros Municípios, de pequeno e médio porte, que não tem conhecimento acumulado, nem como recorrer a especialistas em determinados diagnósticos e terapias e que são demandados a fornecê-los sob as penas da lei. Por vezes, o cumprimento de ordem judicial ou orientação do Ministério público leva a que pequenos Municípios arquem com despesas para um único usuário, o que equivale ao recurso total destinado à atenção básica do seu município. ${ }^{54}$

Tais afirmações vêm ao encontro do que se quer analisar, pois a integralidade da atenção à saúde deve estar em consonância com o preceito constitucional. É o Estado que regula o sistema, com a população, por meio de seus Conselhos de Saúde. Assim, os atos administrativos editados em conformidade à lei devem ser levados em consideração nas decisões judiciais.

Portanto, para a completude da definição do termo integralidade, é necessário que seja feita a conexão entre diagnóstico precoce e oportuno e o atendimento a pessoas que estejam em condições de necessidade de cuidados paliativos. Por exemplo, o tratamento do câncer, pela própria complexidade da doença, exige a aplicação do princípio da integralidade, pois essa é uma espécie de doença que exige integração de procedimentos clínicos e cirúrgicos. Assim, tratar 
essa modalidade de doença, que não se restringe apenas ao aspecto medicamentoso, exige integração entre os procedimentos. $O$ tratamento quimioterápico ou o medicamento isoladamente pouco contribui para os resultados de taxas de mortalidade por câncer.

A partir desses levantamentos, cabe-nos concluir que prevenção, tratamento, integração ou reintegração social, ainda mais amparo psicológico e evolução tecnológica são a mesma face de um mesmo bem jurídico: a saúde.

\section{CONSIDERAÇÕES FINAIS}

A concretude do direito à saúde, afirmada pelo art. 196 da Constituição, não pode ser tomada pela metade, ou seja, o texto deve ser lido e interpretado como um todo. Assim, a leitura da parte inicial "A saúde é direito de todos e dever do Estado" deve ser interligada à segunda, "[...] garantido mediante políticas sociais e econômicas que visem à redução do risco de doença e de outros agravos e ao acesso universal igualitário às ações e serviços para a sua promoção, proteção e recuperação". Ignorar a segunda parte da regra contida no art. 196 do texto constitucional significa negar-lhe a efetividade que foi lhe dada pelo constituinte originário.

A análise realizada neste artigo nos leva a inferir que o direito à saúde, entendido como direito fundamental social, se mostra destinado à promoção do bem comum e à realização da justiça social. É sabido que no País, devido às suas dimensões territoriais, o acesso aos serviços de saúde não se dá de modo proporcional a todos aqueles que o habitam. A universalidade, a igualdade e a integralidade são princípios constitucionais que regem a saúde, portanto mencionados princípios devem ser aplicados por aqueles que possuem, por escolha, a missão de aplicá-los de modo a incluir todos aqueles que dela necessitam. Suas ações não podem ter uma visão parcial da realidade brasileira, ignorando aqueles que mais precisam do amparo estatal para a promoção, proteção ou recuperação da saúde

Os contornos da saúde pública brasileira devem ser definidos pelas políticas públicas, conforme determinação da Constituição Federal, e a sua implementação da mesma, é de atribuição do Poder Legislativo e do Poder Executivo, instâncias políticas democraticamente 
legitimadas. Parafraseando as palavras do ministro Cezar Peluso, é o Poder Legislativo e o Poder Executivo que devem decidir quais são as prioridades da população, em termos de saúde.

Para que seja possível garantir a universalidade das prestações dos serviços de saúde, independentemente do acesso maior ou menor ao Poder Judiciário, é preciso que se faça respeitar a Constituição, pois é esta quem determina que a garantia do direito à saúde seja plenamente realizada por políticas sociais e econômicas, conforme orientação do art. 196. Assim, para que a própria existência do Sistema Único de Saúde não seja, em médio prazo, comprometida, é preciso entender e respeitar as ações determinadas pelo Poder Legislativo como dotadas de presunção de legitimidade e correção.

Não se pode ainda olvidar que o direito à saúde é um direito fundamental social, bem como sua natureza e estrutura, assim, seu escopo é o da promoção do bem comum e a realização da justiça social, com observância aos princípios da equidade e da universalidade de acesso. A consubstanciação do direito à saúde é um direito de milhões de cidadãos brasileiros. A sua conquista exige estratégias e conhecimentos técnicos complexos como foi amplamente mostrado no decorrer deste estudo. Exige-se uma visão geral dos inúmeros problemas que podem interferir para a concretização desse direito, como as proporções continentais e as grandes desigualdades regionais presentes no Brasil. Ao atender ao direito à saúde individualmente, sem lançar olhar sobre todas as dificuldades de implementação desse direito, o Estado torna-se impossibilitado de organizar políticas públicas efetivas em matéria de saúde.

\section{NOTAS}

1 SINDHOSP: Saúde um desafio mundial. Anuário, 2010. p. 59.

2 GANDOLFI, Sueli Dallari; NUNES JÚNIOR, Vidal Serrano. Direito sanitário. São Paulo: Ed.Verbatim, 2010. p. 29.

3 Fonte: Programa das Nações Unidas para o Desenvolvimento (PNUD). Disponível em: <http:// www.pnud.org.br>. Acesso em: 19 ago. 2011.

4 MARQUES, Silvia Badim. Revista de Direito Sanitário, São Paulo v. 10, n. 2, p. 64-86, jul./ out. 2009.

“TITULO $8^{\circ}$ - Das Disposições Geraes, e Garantias dos Direitos Civis, e Politicos dos Cidadãos Brazileiros.

Art. 179. A inviolabilidade dos Direitos Civis, e Políticos dos Cidadãos Brazileiros, que tem por base a liberdade, a segurança individual, e a propriedade, é garantida pela Constituição do Imperio, pela maneira seguinte [...] 
XXIV. Nenhum gênero de trabalho, de cultura, indústria, ou commercio póde ser prohibido, uma vez que não se opponha aos costumes publicos, á segurança, e saude dos Cidadãos [...]. XXXI. A Constituição também garante os socorros públicos" (Disponível em: <http:// www.planalto.gov.br/ccivil_03/constituição/Constituição91.htm>. Acesso em: 18 ago. 2011).

5 GANDOLFI, Sueli Dallari; NUNES JÚNIOR, Vidal Serrano. Direito sanitário. São Paulo: Ed.Verbatim, 2010. p. 54.

6 BULOS, Uadi Lammêgo. Constituição federal anotada. São Paulo: Ed. Saraiva, 2005. p. 59

7 CONSTITUIÇÃO DA REPÚBLICA DOS ESTADOS UNIDOS DO BRASIL (DE 16 DE JULHO DE 1934) - “Art 10 - Compete concorrentemente à União e aos Estados:

[...] II - cuidar da saúde e assistência públicas;

[...] Art 121 - A lei promoverá o amparo da produção e estabelecerá as condições do trabalho, na cidade e nos campos, tendo em vista a proteção social do trabalhador e os interesses econômicos do País.

[...] h) assistência médica e sanitária ao trabalhador e à gestante, assegurando a esta descanso antes e depois do parto, sem prejuízo do salário e do emprego, e instituição de previdência, mediante contribuição igual da União, do empregador e do empregado, a favor da velhice, da invalidez, da maternidade e nos casos de acidentes de trabalho ou de morte [...]".

8 "Art. 138 - Incumbe à União, aos Estados e aos Municípios, nos termos das leis respectivas: [...] f) adotar medidas legislativas e administrativas tendentes a restringir a moralidade e a morbidade infantis; e de higiene social, que impeçam a propagação das doenças transmissíveis;

Art 140 - A União organizará o serviço nacional de combate às grandes endemias do País, cabendo-lhe o custeio, a direção técnica e administrativa nas zonas onde a execução do mesmo exceder as possibilidades dos governos locais" (Disponível em: <http:/ / www.planalto.gov. br/ccivil_03/constituição/constitui\%C3\%A7ao34.htm>. Acesso em: 18 ago. 2011).

9 GANDOLFI, Sueli Dallari; NUNES JUNIOR, Vidal Serrano. Direito sanitário. São Paulo: Ed.Verbatim, 2010. p. 55.

10 BULOS, Uadi Lammêgo. Constituição federal anotada. São Paulo: Saraiva, 2005. p. 60 "Isto ocorreu devido ao poder discricionário que lhe foi atribuído para submeter ao Parlamento Nacional qualquer lei declarada inconstitucional pelo judiciário. Se essa declaração de inconstitucionalidade, reexaminada pelo legislativo, viesse a ser confirmada pelo voto de dois terços de ambas as Casas, a decisão judicial ficaria sem efeito."

11 "Art 16 - Compete privativamente à União o poder de legislar sobre as seguintes matérias: [...] XXVII - normas fundamentais da defesa e proteção da saúde, especialmente da saúde da criança".

12 "Art 18 - Independentemente de autorização, os Estados podem legislar, no caso de haver lei federal sobre a matéria, para suprir-lhes as deficiências ou atender às peculiaridades locais, desde que não dispensem ou diminuam as exigências da lei federal, ou, em não havendo lei federal e até que esta regule, sobre os seguintes assuntos:

[...] c) assistência pública, obras de higiene popular, casas de saúde, clínicas, estações de clima e fontes medicinais [...]" Disponível em: <http://www.planalto.gov.br/ccivil_03/ constituição/constitui\%C3\%A7ao37.htm>. Acesso em: 18 ago. 2011.

13 BULOS, Uadi Lammêgo, op.cit., p. 60

14 "Art $5^{\circ}$ - Compete à União:

[...] XV - legislar sobre:

[...] b) normas gerais de direito financeiro; de seguro e previdência social; de defesa e proteção da saúde; e de regime penitenciário [...]".

15 Idem, p. 61.

16 DALLARI, Sueli Gandolfi; NUNES JÚNIOR, Vidal Serrano. Direito sanitário. São Paulo: Ed. Verbatim, 2010. p. 55.

17 BARRETO JUNIOR, Irineu Francisco. Aspectos históricos e normativos da política pública de saúde no Brasil. FMU Direito: Revista da Faculdade de Direito das Faculdades Metropolitanas de São Paulo, São Paulo, v. 20, n. 28, p. 126-135, 2006. 
18 “Art 158 - A Constituição assegura aos trabalhadores os seguintes direitos, além de outros que, nos termos da lei, visem à melhoria, de sua condição social:

[...] IX - higiene e segurança do trabalho;

[...] XV - assistência sanitária, hospitalar e médica preventiva [...]" (Disponível em: <http:// www.planalto.gov.br/ccivil_03/constituição/constitui\%C3\%A7ao67.htm>. Acesso em: 18 ago. 2011).

19 SILVA, José Afonso. Curso de direito constitucional positivo, 14. ed. rev., São Paulo: Malheiros, 1997. p. 88.

20 “Art. 165. A Constituição assegura aos trabalhadores os seguintes direitos, além de outros que, nos têrmos da lei, visem à melhoria de sua condição social:

[...] XV - assistência sanitária, hospitalar e médica preventiva [...]" (Disponível em: <http:// www.planalto.gov.br/ccivil_03/constituição/emendas/emc_anterior1988/emc01-69.htm>. Acesso em: 20 ago. 2011.

21 BULOS, Uadi Lammêgo, op. cit., p. 63

22 BARRETO JUNIOR, Irineu Francisco. Aspectos históricos e normativos da política pública de saúde no Brasil. FMU Direito: Revista da Faculdade de Direito das Faculdades Metropolitanas de São Paulo, São Paulo, v. 20, n. 28, p. 126-135, 2006.

23 BARRETO JÚNIOR, Irineu Francisco. Poder local e política: a saúde como locus de embate na cidade de Santos - SP. 2005. Tese (Doutorado em Ciências Sociais) - Pontifícia Universidade Católica de São Paulo, São Paulo, 2005. p. 1.

24 A Lei Complementar (LC) no 11, de 25 de maio de 1971, estabelecia que "[...] os serviços de saúde serão prestados aos beneficiários, na escala que permitirem os recursos orçamentários do Funrural, em regime de gratuidade total ou parcial, segundo a renda familiar do trabalhador ou dependente", e estes eram disponibilizados principalmente por meio de convênios com entidades sindicais e filantrópicas.

25 PIOLA, Francisco Sérgio e et al. Vinte anos da Constituição de 1988: o que significaram para a saúde da população brasileira. São Paulo. Disponível em: <http://ipea.gov.br/ sites/000/2/publicacoes/bpsociais/bps_17volume01/06_cap03.pdf>. Acesso em: 18 jul. 2011. p. 105.

26 Ibidem

27 CONSELHO NACIONAL DE SECRETÁRIOS MUNICIPAIS DE SAÚDE (CONASEMS). Movimento sanitário na década de 1970: a participação das universidades e município. Memórias. Brasília, 2007. p. 45.

28 "[...] concepção de saúde como direito universal de cidadania; compreensão da determinação da saúde e doença pelas relações econômicas e sociais prevalentes; responsabilidade do Estado na garantia do direito e a necessidade de criar um sistema público unificado de saúde e de livre acesso à população; participação e o controle direto, isto é, o controle social deste sistema unificado por representantes da população e das entidades civis da sociedade". (Disponível em: <http:// ipea.gov.br/sites/000/2/publicacoes/bpsociais/ bps>. Acesso em: 18 jul. 2011. p. 107).

29 BULOS, Uadi Lammêgo. Constituição federal anotada. São Paulo: Ed. Saraiva, 2005. p. 63.

30 Idem, p. 63

31 CORDEIRO, Hésio. Descentralização, universalidade e equidade nas reformas da saúde. Ciênc. Saúde Coletiva, São Paulo, v. 6, n. 2, 2001. Disponível em: <http:/ / www.scielo.br/ scielo.php?script=sci_arttext\&pid=S1413-81232001000200004\&lng=en\&nrm=iso $>$. Acesso em: 25 ago. 2011.

32 BASTOS, Celso Ribeiro. Hermenêutica e interpretação constitucional. São Paulo: Celso Bastos Editor: Instituto Brasileiro de Direito Constitucional, 1997. p. 80.

33 BRASIL. Supremo Tribunal federal (STF). A Constituição e o Supremo. 3. ed. Brasília: Secretaria de Documentação, 2010. p. 1309.

34 BASTOS, Celso Ribeiro. Hermenêutica e interpretação constitucional. São Paulo: Celso Bastos Editor: Instituto Brasileiro de Direito Constitucional, 1997. p. 8.

35 “RE 393175 AgR / RS - RIO GRANDE DO SUL: Min. CELSO DE MELLO. Julgamento: 12-12-2006 Publicação DJ 02-02-2007 PP - 00140. EMENT VOL - 02262-08PP-01524". 
36 PIOLA, Francisco Sérgio et al. Vinte anos da Constituição de 1988: o que significaram para a saúde da população brasileira. São Paulo. Disponível em: <http:/ /ipea.gov.br/sites/000/2/ publicacoes/bpsociais/bps_17volume01/06_cap03.pdf>. Acesso em: 18 jul. 2011.

37 O conceito de Relevância Pública na Constituição Federal. Série Direito e Saúde no 1 . Publicação da Organização Panamericana da Saúde. Brasília/1994, p. 40.

38 FERRAZ, Octávio Luiz Motta; VIEIRA, Fabíola Sulpino. Direito à saúde, políticas públicas e desigualdades sociais no Brasil: equidade como princípio fundamental. São Paulo: Faculdade de Direito da Universidade de São Paulo, 2007. p. 15.

39 BORGES, Danielle da Costa Leite; UGÁ, Maria Alicia Domingues. Conflitos e impasses da judicialização na obtenção de medicamentos: as decisões de $1^{\mathrm{a}}$ instância nas ações individuais contra o Estado do Rio de Janeiro, Brasil, em 2005. Cad. Saúde Pública, Rio de Janeiro, v. 26, n. 1, p. 59-69, jan. 2010.

40 OLIVEIRA, Maria Auxiliadora, et al. Assistência farmacêutica e acesso a medicamentos. Rio de Janeiro: Editora Fiocruz, 2007. p. 91-92.

41 KELBERT, Fabiana Okchstein. Reserva do possível e a efetividade dos direitos sociais no direito brasileiro. Porto Alegre: Ed. Livraria do Advogado, 2011. p. 69.

42 OLSEN, Ana Carolina Lopes. Direitos fundamentais sociais: efetividade frente à reserva do possível. Curitiba: Juruá, 2008. p. 208.

43 KRELL, Andreas J. Direitos sociais e controle judicial no Brasil e na Alemanha. Porto Alegre: Sergio Antonio Fabris Editor, 2002. p. 52.

44 “Art. 198. As ações e serviços públicos de saúde integram uma rede regionalizada e hierarquizada e constituem um sistema único, organizado de acordo com as seguintes diretrizes: $\S 2^{\circ}$ A União, os Estados, o Distrito Federal e os Municípios aplicarão, anualmente, em ações e serviços públicos de saúde recursos mínimos derivados da aplicação de percentuais calculados sobre: [...]"

45 “Art. 212. A União aplicará, anualmente, nunca menos de dezoito, e os Estados, o Distrito Federal e os Municípios vinte e cinco por cento, no mínimo, da receita resultante de impostos, compreendida a proveniente de transferências, na manutenção e desenvolvimento do ensino".

46 BORGES, Danielle da Costa Leite; UGÁ, Maria Alicia Domingues. Conflitos e impasses da judicialização na obtenção de medicamentos: as decisões de $1^{\mathrm{a}}$ instância nas ações individuais contra o Estado do Rio de Janeiro, Brasil, em 2005. Cad. Saúde Pública, Rio de Janeiro, v. 26, n. 1, p. 59-69, jan. 2010, p. 16.

47 NASCIMENTO, Tupinambá Miguel Castro do. A ordem social e a nova Constituição. Rio de Janeiro: Ed. Aide, 1991. p. 260.

48 DALLARI, Sueli Gandolfi; NUNES JÚNIOR, Vidal Serrano. Direito sanitário. São Paulo. Ed.Verbatim, 2010. p. 75.

49 Ibid. p. 55.

50 Instituto de Pesquisa Econômica Aplicada. Políticas Sociais: Acompanhamento e análise, p. 112.

51 MASCARENHAS, Rodrigo Tostes de Alencar - subprocurador-geral do Estado do Rio de Janeiro - Audiência Pública: Saúde/Supremo Tribunal Federal. Brasília: Secretaria de Documentação, Coordenadoria de Divulgação de Jurisprudência, 2009. p. 111.

52 Audiência pública: saúde/Supremo Tribunal Federal. Brasília: Secretaria de Documentação, Coordenadoria de Divulgação de Jurisprudência, 2009. p. 237

53 MARQUES, Silvia Badim. A relação do sistema jurídico e do sistema político na garantia do direito social à assistência farmacêutica: o caso do Estado de São Paulo. 2005. Dissertação (Mestrado em Saúde Pública) - Programa de Pós-Graduação em Saúde Pública, Universidade de São Paulo, São Paulo, 2005. p. 123.

54 NARDI, Antonio Carlos Figueiredo - presidente do Conselho nacional de Secretários Municipais de Saúde -Audiência Pública: Saúde/Supremo Tribunal Federal. Brasília: Secretaria de Documentação, Coordenadoria de Divulgação de Jurisprudência, 2009. p. 250. 


\section{REFERÊNCIAS}

BARRETO JÚNIOR, Irineu Francisco. Poder local e política: a saúde como locus de embate na cidade de Santos - SP. 2005. Tese (Doutorado em Ciências Sociais) - Pontifícia Universidade Católica de São Paulo, São Paulo, 2005.

Aspectos históricos e normativos da política pública de saúde no Brasil. FMU Direito: Revista da Faculdade de Direito das Faculdades Metropolitanas de São Paulo, São Paulo, v. 20, n. 28, p. 126-135, 2006.

BASTOS, Celso Ribeiro. Hermenêutica e interpretação constitucional. São Paulo: Celso Bastos Editor: Instituto Brasileiro de Direito Constitucional, 1997.

BORGES, Danielle da Costa Leite; UGÁ, Maria Alicia Domingues. Conflitos e impasses da judicialização na obtenção de medicamentos: as decisões de $1^{\mathrm{a}}$ instância nas ações individuais contra o Estado do Rio de Janeiro, Brasil, em 2005. Cad. Saúde Pública, Rio de Janeiro, v. 26, n. 1, p. 59-69, jan. 2010.

BRASIL. Supremo Tribunal Federal (STF). A Constituição e o Supremo. 3. ed. Brasília: Secretaria de Documentação, 2010.

BULOS, Uadi Lammêgo. Constituição federal anotada. São Paulo: Ed. Saraiva, 2005.

CONSELHO NACIONAL DE SECRETÁRIOS MUNICIPAIS DE SAÚDE (Conasems). Movimento sanitário na década de 1970: a participação das universidades e município. Memórias. Brasília, 2007.

CORDEIRO, Hésio. Descentralização, universalidade e equidade nas reformas da saúde. Ciência e Saúde Coletiva, São Paulo, v. 6, n. 2, 2001.

FERRAZ, Octávio Luiz Motta; VIEIRA, Fabíola Sulpino. Direito à saúde, políticas públicas e desigualdades sociais no Brasil: equidade como princípio fundamental. São Paulo: Faculdade de Direito da Universidade de São Paulo, 2007. 
GANDOLFI, Sueli Dallari; NUNES JÚNIOR, Vidal Serrano. Direito sanitário. São Paulo: Ed.Verbatim, 2010.

KELBERT, Fabiana Okchstein. Reserva do possível e a efetividade dos direitos sociais no direito brasileiro. Porto Alegre: Ed. Livraria do Advogado, 2011.

KRELL, Andreas J. Direitos sociais e controle judicial no Brasil e na Alemanha. Porto Alegre: Sergio Antonio Fabris Editor, 2002.

MARQUES, Silvia Badim. A relação do sistema jurídico e do sistema político na garantia do direito social à assistência farmacêutica: 0 caso do Estado de São Paulo. 2005. Dissertação (Mestrado em Saúde Pública) - Programa de Pós-Graduação em Saúde Pública, Universidade de São Paulo, São Paulo, 2005.

MARQUES, Silvia Badim. Revista de Direito Sanitário, São Paulo v. 10, n. 2 p. 64-86 jul./out. 2009.

MASCARENHAS, Rodrigo Tostes de Alencar - subprocurador-geral do Estado do Rio de Janeiro. Audiência Pública: Saúde / Supremo Tribunal Federal. Brasília: Secretaria de Documentação, Coordenadoria de Divulgação de Jurisprudência, 2009.

NARDI, Antonio Carlos Figueiredo - Presidente do Conselho Nacional de Secretários Municipais de Saúde - Audiência Pública: Saúde / Supremo Tribunal Federal. Brasília: Secretaria de Documentação, Coordenadoria de Divulgação de Jurisprudência, 2009.

NASCIMENTO, Tupinambá Miguel Castro do. A ordem social e a nova Constituição. Rio de Janeiro: Ed. Aide, 1991.

OLIVEIRA, Maria Auxiliadora et al. Assistência farmacêutica e acesso a medicamentos. Rio de Janeiro: Editora Fiocruz, 2007.

OLSEN, Ana Carolina Lopes. Direitos fundamentais sociais: efetividade frente à reserva do possível. Curitiba: Juruá, 2008. 
PIOLA, Francisco Sérgio et al. Vinte anos da Constituição de 1988: o que significaram para a saúde da população brasileira. São Paulo. Disponível em: <http://ipea.gov.br/sites/000/2/publicacoes/bpsociais/ bps_17volume01/06_cap03.pdf>. Acesso em: 18 jul. 2011.

PROGRAMA DAS NAÇÕES UNIDAS PARA O DESENVOLVIMENTO (PNUD). Disponível em: <http:/ / www.pnud.org.br>. Acesso em: 19 ago. 2011.

SILVA, José Afonso. Curso de direito constitucional positivo, 14. ed. rev., São Paulo: Malheiros Ed., 1997.

SINDHOSP: Saúde um desafio mundial. Anuário, 2010.

Artigo recebido em: 20-7-2012

Aprovado em: 19-11-2013

\section{Irineu Francisco Barreto Júnior}

Doutor em Ciências Sociais pela Pontifícia Universidade Católica de São Paulo (PUC-SP); mestre em Ciências Sociais pela Pontifícia Universidade Católica de São Paulo (PUC-SP); docente do Programa de Mestrado em Direito da Sociedade da Informação da FMU, Professor e Coordenador Adjunto do Curso de Graduação em Direito das Faculdades Metropolitanas Unidas FMU.

Av. Casper Líbero, 464, Luz. CEP 01033-000 - Sao Paulo, SP.

E-mail: ifbjunio@seade.gov.br

\section{Miriam Pavani}

Mestre em Direito da Sociedade da Informação pelas Faculdades Metropolitanas Unidas (FMU-SP); procuradora do município de Mogi Guaçu e professora do Curso de Graduação em Direito da Faculdade Mogiana do Estado de São Paulo (Famoesp).

Prefeitura Municipal de Mogi Guaçu, Secretaria de Negócios Jurídicos. Rua Henrique Coppi. Morro do Ouro. CEP 13840000 - Mogi Guaçu, SP. 13845318.

E-mail: mpavany@hotmail.com 
